\title{
Cognitive Functioning and Life Quality of the Elderly: A Cross-sectional Study
}

\author{
Mirjana Kralj-Vasilj ${ }^{1,2,}$ Štefica Mikšić ${ }^{1}$, Nikolina Farčić ${ }^{1,2,3}$, Dunja Degmenčić ${ }^{2,3}$, Maja Miškulin ${ }^{2,3}$, Kasandra Musović ${ }^{1}$, Ivana Barać ${ }^{1}$ \\ ${ }^{1}$ Josip Juraj Strossmayer University of Osijek, Faculty of Dental Medicine and Health Osijek, Nursing Institute "Professor \\ Radivoje Radić", Crkvena 21, HR-31000 Osijek, Croatia; ' Josip Juraj Strossmayer University of Osijek, Faculty of Medicine, \\ Josipa Huttlera 4, HR-31000 Osijek, Croatia; ${ }^{3}$ University Hospital Centre Osijek, Josipa Huttlera 4, HR-31000 Osijek, Croatia
}

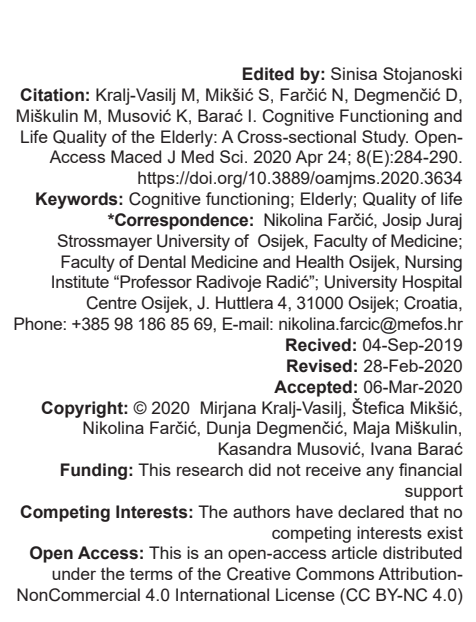

\section{Introduction}

Thanks to the general life standard growth and health-care improvements and as a direct consequence of lowering the natural increase the life expectancy has been extended. People live longer, there is an increasing number of people over 65 years of age [1]. According to the Gerontological Health Statistics for Croatia, the number of the elderly people in Croatia is increasingly growing. The UN classification ranks the Republic of Croatia as the country which belongs to group four of the European countries with elderly population. The percentage of the elderly in Croatia is $17.6 \%$ of the total population, according to the Croatian Bureau of Statistics. By the year 2050, the total percentage is expected to grow and reach as far as $26.8 \%$ [1]. According to one of the most common factors, when it comes to analyzing aging, the median age of the population, the Croatian population is considered to be exceedingly old. When compared with $27 \mathrm{EU}$ states that have been analyzed this way, the Republic of Croatia is on the high eighth place with its median age being 41.5 years. Another reason for Croatia to be among the European top countries is the high number of the elderly population (65 years of age and over) despite the fact that the elderly mortality and life expectancy are lower if compared to the other EU states. By the year 2020, the percentage of the elderly (over 65 years of age) will have gone up over $20 \%$ and the predictions are that by the year 2050 every third Croatian resident might be over 65 years of age. What is certain, is that the entire population is growing old along with its part of the population that is already old. By the year 2020, more than $5 \%$ of the population is going to be older than 80 years of age. Moreover, by the year 2050 that percentage will have doubled making every tenth Croatian resident older than 80 years of age [2].

The activity of a healthy older person never fully stops; it just changes its form. Reaching certain age just means that people should adapt to new activities after retiring. It is a time for personal growth, challenges, and development of new roles in one's life. 
The aging of the body both indirectly and directly influences human behavior and understanding. Directly by disabling life functions, indirectly by influencing the mental abilities. Especially strong indirect influence is caused by the outer, appearance changing aging signs (thin and grey hair, creases, missing teeth, age spots, gain or loss of weight, hunchback posture), regardless of the degree at which they really disturb the life functions of individuals [3].

The life risks for the elderly are caused by the discrepancy between their lowering psycho-physical features and the ability to adapt to the demands set by the environment. By interacting with the environment, risks of various intensity appear which cause the elderly significant problems for their life quality; most frequently these are physical risks (rapid body transformations, illnesses, poor diet, and unadapt environment), mental risks (loneliness, feeling of being lost, alienation, and loss of purpose of living), social risks (social alienation, and unadapt environment), socio-economic risks, socio-health, socio-cultural, socio-urban, and many other different types of risks [4], [5].

The World Health Organization (WHO) defines mental health as "a state of well-being in which every individual realizes his or her own potential, can cope with the normal stresses of life, can work productively and fruitfully, and is able to make a contribution to her or his community" [6].

The elderly are exposed to a continuous threat of being alone; they interact less socially, have weak health and are facing the gradual lowering and disintegration of their cognitive functions. Precisely these mental disorders are one of the most frequent reasons of their retirement. The prevalence of dementia and pre-dementia is high with the elderly population [7]. According to research, the elderly population sometimes feels lonely and suffers from depression attacks [8].

After reaching a certain age, the elderly seems to exhibit the lowering in cognitive functioning which along with the aforementioned factors means the lowering of the life quality in total [9]. The problems regarding the life quality occur as a direct consequence of the gap between the possibilities of the elderly and the demands and conditions set by modern life [9]. The WHO defines quality of life (QOL) as one's perception of their position in life in the context of the culture and the value systems in which they live and in relation to their goals, expectations, standards, and concerns [6]. The QOL of an individual depends on one's ability to compensate for any disadvantages one feels burdened by and using the opportunities for one's own advantage, which in the end results by achieving balance between one's expectations and reality [10]. The quality of health is estimated by the life expectancy, social possibilities under the influence of illnesses, illness treatments or social welfare policies, and health protection. The aim of this paper is to research cognitive functioning and life quality of the elderly.

\section{Subjects and Methods}

\section{Subjects}

The research participants were elderly people of 65 years of age or more who live in their own households in the Osječko-Baranjska County. Exclusion criteria were elderly with present dementia. The participants have been chosen by including every fifth person from the family medicine charts. The research was composed according to the principle of the crosssectional study. The data have been collected during the period between March 2016 and October of 2016.

\section{Methods}

Data used for cognitive functioning and QOL assessment have been obtained from the questionnaires. The data referring to prescriptions and use of psychofarmacs including the presence of various somatic and mental illnesses have been obtained by analyzing the participants' medical documentation. The data have been gathered using specially assembled anonymous questionnaires for the purposes of this research: For socio-demographic data, and for general information about the participant (age, sex, residence, family status, and education).

Mini-mental state examination (MMSE) questionnaire [11] for quick cognitive abilities assessment comprised out of 11 questions for evaluating time, space, and person mental orientation, which is also used to test the short-term memory, the ability of abstract thinking, and understanding.

The final instrument used was the WHOQOL (WHO-QOL-BREF) scale [12]. WHOQOL-BREF scale is used to assess the person's perception in the context of their own culture, their system of values and personal goals, standards, and care. The measuring instrument contains 24 elements divided into four categories presenting different life domains (the domain of physical and mental health, social relations, and the environment).

All the gathered data were used only for the purposes of this research and in no other way do they disturbed the privacy or well-being of the participants.

\section{Statistical data analysis}

Categorical data are presented in the form of absolute and relative frequencies. Numerical data aare described by median and interquartile range. Normal distribution of the numerical variables is to be tested by Shapiro-Wilk Test. The differences of the numerical variables between two independent groups are tested by Mann-Whitney U-test. The correlation between the variables is determined by the Spearman's rank correlation coefficient (Rho). All the $p$ values are 
two-tailed. The level of significance is set on $p=0.05$.

Statistical program MedCalc (version 16.2.0, MedCalc Software bvba, Ostend Belgium) is used for the purposes of the statistical analysis.

\section{Ethical consideration}

The study was approved by the Institutional Ethics Committee of the Faculty of Medicine, Josip Juraj Strossmayer University of Osijek, and permission to access participants' medical documentation was obtained from ethics committees from Health Centre Osijek and Health Centre Đakovo and participants themselves. The researchers previously contacted all participants included in the study and were thoroughly informed and their written consent was obtained before inclusion in the study. To ensure anonymity, all of the participants were marked by number that could not be traced back to their identity. Participation in the study was entirely voluntary. The research was performed in accordance with ethical standards laid down in the 1964 Declaration of Helsinki and the code of ethics for nurses of Croatia.

\section{Results}

A total of 156 participants whose average age is 75 participated in the research (standard deviation 7 years), the span being between 65 and 93 years of age. There were 112 female $(72 \%)$ participants. Most of them live in the city 74 (47\%), and 72 participants $(46 \%)$ are married. Most of the participants have finished their secondary education. Thirty-seven (24\%) participants suffer only from a physical illness, 117 (75\%) participants suffer both from physical and mental illnesses. The most common physical illnesses $103(66 \%)$ participants suffer from are heart and blood vessel illnesses, whereas 37 (24\%) participants suffer from a depressive disorder (Table 1).

Sixty-two (39\%) participants permanently use psychofarmacs, 48 (31\%) participants use anxiolytics; and $43(28 \%)$ have been using them for a period longer than 5 years. Thirty-sis (23\%) participants avoid, whereas 67 (43\%) regularly go to doctor examinations. Family physicians prescribe psychofarmacs for $128(82 \%)$ participants and only $28(18 \%)$ receive their medication from a specialist doctor - a psychiatrist.

The QOL was assessed by using WHOQOLBREF scale. Fifty-seven (37\%) participants consider their QOL to be good, 44 (28\%) participants are displeased by it, and 12 (8\%) very displeased (Table 2).

Forty-seven (30\%) participants have enough energy for everyday activities. To function properly on daily basis $9(6 \%)$ participants need medical
Table 1: Basic characteristics of the participants

\begin{tabular}{ll}
\hline Variable & $\mathrm{n}(\%)$ participants \\
\hline Gender & \\
Male & $44(28)$ \\
Female & $112(72)$ \\
Place of residence & \\
City & $74(47)$ \\
Suburban settlement & $19(12)$ \\
Village & $63(41)$ \\
Family status & \\
Married & $72(46)$ \\
Widow & $70(45)$ \\
Divorced & $9(6)$ \\
Single & $5(3)$ \\
Level of education & \\
Non-finished elementary school education & $28(18)$ \\
Elementary school education & $53(34)$ \\
Secondary education & $61(39)$ \\
College education & $10(6)$ \\
University degree & $4(3)$ \\
Physical illness & \\
Cardiovascular diseases & $103(66)$ \\
Rheumatic diseases & $101(65)$ \\
Endocrinological diseases & $26(17)$ \\
Lung diseases and allergies & $24(15)$ \\
Digestive diseases & $32(21)$ \\
Kidney diseases & $27(17)$ \\
Skin diseases & $18(12)$ \\
Cancers & $15(7)$ \\
Other diseases & $49(31)$ \\
Mental illness & \\
Depressive disorders & $37(24)$ \\
Anxiety disorders & $58(37)$ \\
Psychotic disorders & $12(8)$ \\
Insomnia & $58(37)$ \\
Psycho-organic syndrome (dementia) & $12(8)$ \\
Alcoholism & $10(6)$ \\
\hline
\end{tabular}

treatment. Fifty-seven (37\%) participants claim to be satisfied with their sleep; $47(30 \%)$ say that they are generally satisfied with their working abilities; and $56(36 \%)$ say that they generally feel their lives are purposeful. Most of them, 59 (38\%) participants, are able to fully concentrate. Thirty-eight (24\%) participants are either very dissatisfied or dissatisfied with themselves.

Table 2: Self-assessment of the quality of life and health

\begin{tabular}{|c|c|c|c|c|c|c|}
\hline \multirow{2}{*}{$\begin{array}{l}\text { Self-assessment } \\
\text { of the quality of } \\
\text { life and health }\end{array}$} & \multicolumn{6}{|c|}{$\mathrm{n}(\%)$ participants } \\
\hline & $\begin{array}{l}\text { Very } \\
\text { bad }\end{array}$ & Bad & $\begin{array}{l}\text { Neither bad } \\
\text { nor good }\end{array}$ & Good & $\begin{array}{l}\text { Very } \\
\text { good }\end{array}$ & In total \\
\hline \multirow{2}{*}{$\begin{array}{l}\text { How would you } \\
\text { rate your quality } \\
\text { of life? }\end{array}$} & $7(4)$ & $22(14)$ & $55(35)$ & $57(37)$ & $15(10)$ & $\begin{array}{l}156 \\
(100)\end{array}$ \\
\hline & $\begin{array}{l}\text { Very } \\
\text { displeased }\end{array}$ & Displeased & $\begin{array}{l}\text { Neither } \\
\text { satisfied nor } \\
\text { dissatisfied }\end{array}$ & Satisfied & $\begin{array}{l}\text { Very } \\
\text { satisfied }\end{array}$ & In total \\
\hline $\begin{array}{l}\text { How satisfied } \\
\text { are you with your } \\
\text { health? }\end{array}$ & $12(8)$ & $44(28)$ & $48(31)$ & $47(30)$ & $5(3)$ & $\begin{array}{l}156 \\
(100)\end{array}$ \\
\hline
\end{tabular}

Seventy-nine (51\%) participants claim to frequently and very frequently feel sadness, despair, anxiety, or depression. Seventy-six (49\%) participants say that their personal relations are on a satisfactory level. Furthermore, 104 (67\%) participants claim to have access to all the information essential for their everyday life. Ninety-five (61\%) are satisfied with the health services availability.

The highest mark was in the environment domain, median 64.3 (interquartile range from 53.6 to 75 ) in the range from 14.3 to 92.9 (Table 3 ).

Table 3: Medians of the quality of life domain

\begin{tabular}{lll}
\hline Domain & Median (interquartile range) & Minimum-Maximum \\
\hline Physical health & $57.1(46.4-64.3)$ & $28.6-85.7$ \\
Mental health & $54.2(41.7-62.5)$ & $16.7-87.5$ \\
Social functioning & $50(41.7-66.7)$ & $0-91.7$ \\
Environment & $64.3(53.6-75)$ & $14.3-92.9$ \\
\hline
\end{tabular}


The MMSE questionnaire, median 24 (interquartile range 16-28) with the range from 4 to 30 was used as an instrument for quick cognitive functioning assessment and dementia diagnostics. According to the division where the result 24 and over represents the normal test results, our research has shown that 83 (53\%) participants have normal, whereas $73(47 \%)$ participants' test results indicate the presence of a particular disorder. The life quality of the participants whose test results indicate the presence of a particular disorder is notably lower in all the measured domains (Table 4).

Table 4: Central values of the quality of life domains according to the MMSE test results

\begin{tabular}{|c|c|c|c|}
\hline \multirow[t]{2}{*}{ Domain } & \multicolumn{2}{|c|}{$\begin{array}{l}\text { Median (interquartile range) according to the } \\
\text { MMSE test results }\end{array}$} & \multirow[t]{2}{*}{ p value* } \\
\hline & $\begin{array}{l}\text { Normal test } \\
\text { results }(n=83)\end{array}$ & $\begin{array}{l}\text { Test results indicating a } \\
\text { disorder }(n=73)\end{array}$ & \\
\hline Physical health & $53.6(78.6-60.7)$ & $39.3(85.7-46.4)$ & $<0.001$ \\
\hline Mental health & $54.2(87.5-62.5)$ & $37.5(75-45.8)$ & $<0.001$ \\
\hline Social functioning & $50(83.3-58.3)$ & $33.3(91.7-50)$ & $<0.001$ \\
\hline Environment & 60.7 (92.9-71.4) & $46.4(92.9-57.1)$ & $<0.001$ \\
\hline
\end{tabular}

The participants suffering only from a physical illness exhibit significantly lower values in the environmental domain (Mann-Whitney U-test, $p=0.010$ ) when compared to those suffering both from physical and mental illness whose results show extremely low values in practically all the segments regarding the life quality (Table 5).

Table 5: Central values of the quality of life domain according to the MMSE test results of the participants suffering from specific illnesses

\begin{tabular}{|c|c|c|c|}
\hline \multirow[t]{2}{*}{ Domain } & \multicolumn{2}{|c|}{$\begin{array}{l}\text { Median (interquartile range) according to the } \\
\text { MMSE test results }\end{array}$} & \multirow[t]{2}{*}{$p$ value ${ }^{*}$} \\
\hline & Normal test results & $\begin{array}{l}\text { Test results indicating a } \\
\text { disorder }\end{array}$ & \\
\hline \multicolumn{4}{|c|}{$\begin{array}{l}\text { Suffering only from a physical illness ( } n=26 \text { normal MMSE and } n=11 \text { MMSE indicating a } \\
\text { disorder) }\end{array}$} \\
\hline Physical health & $59.8(75-64.3)$ & $46.4(67.9-60.7)$ & 0.103 \\
\hline Mental health & $54.2(79.2-66.7)$ & $37.5(75-54.2)$ & 0.065 \\
\hline Social functioning & $50(83.3-66.7)$ & $50(83.3-58.3)$ & 0.398 \\
\hline Environment & $64.3(92.9-71.4)$ & $50(75-64.3)$ & 0.010 \\
\hline \multicolumn{4}{|c|}{ Suffering only from a mental illness $(n=2)$} \\
\hline Physical health & $45.5(64.3-62.5)$ & - & - \\
\hline Mental health & $34.4(70.8-58.3)$ & - & - \\
\hline Social functioning & $37.5(66.7-58.3)$ & - & - \\
\hline Environment & $53.6(75-73.2)$ & - & - \\
\hline \multicolumn{4}{|c|}{$\begin{array}{l}\text { Suffering both from physical and mental illnesses ( } n=55 \text { normal MMSE i n=62 MMSE } \\
\text { indicating a disorder) }\end{array}$} \\
\hline Physical health & $53.6(78.6-57.1)$ & $39.3(85.7-46.4)$ & $<0.001$ \\
\hline Mental health & $50(87.5-62.5)$ & $37.5(75-45.8)$ & $<0.001$ \\
\hline Social functioning & $41.7(83.3-58.3)$ & $33.3(91.7-41.7)$ & 0.001 \\
\hline Environment & $60.7(92.9-71.4)$ & $46.4(92.9-55.4)$ & $<0.001$ \\
\hline
\end{tabular}

The values of the cognitive functioning questionnaire are related to the life quality domains; the strongest connection relates to mental health (Spearman`s Rank Correlation Coefficient Rho $=0.493$ $p<0.001$ ) and the weakest connection refers to social functioning (Table 6).

Table 6: The connection between the MMSE test results and the quality of life domains

\begin{tabular}{|c|c|c|}
\hline Domain & $\begin{array}{l}\text { Spearman's correlation coefficient (Rho) } \\
\text { Cognitive abilities (MMSE) }\end{array}$ & $\mathrm{p}$ value \\
\hline Physical health & 0.430 & $<0.001$ \\
\hline Mental health & 0.493 & $<0.001$ \\
\hline Social functioning & 0.322 & $<0.001$ \\
\hline Environment & 0.470 & $<0.001$ \\
\hline
\end{tabular}

\section{Discussion}

This research was conducted with the purpose of establishing the connection between the cognitive functioning and the QOL of the elderly. During the past decades, demographic aging is present worldwide. Between the year 1950 and 2010, the average life expectancy increased from 46 years of age to 68, and by the end of this year it will have risen to 81 years of age. Nowadays worldwide, there are almost 700 million people older than 60 , and it is estimated that this number will have risen to 2 billion by the year 2050 [13].

This research shows that the average age of the participants is 75 and that most of them have suffered from both a particular physical and mental illness. Due to the specific features of aging, such as loss of autonomy, inability to satisfy one's biological and social needs, lowering of one's physical, and mental capacities there is a higher risk of a person being affected by various illnesses including the development of mental disorders in the elderly population [14], [15].

More than a half of the participants in this research suffer from anxiety disorders and insomnia, while most of them also claim to suffer from depressive disorders. Old age-related anxiety has its specificities such as fear from falling, which is more typical for old age [16], even though it generally is not that different from younger age-related anxiety [17]. The anxiety is, moreover, connected with memory loss from which it cannot be separated, making its presence a strong predicament of future cognitive failure. Memory loss is considered to be the initial problem on which anxiety is based [18].

According to the Berlin Aging Study, the anxiety prevalence is $4.5 \%$ affecting people over 70 years of age, divided in a younger (70-84 years) and an older (85-103) group. The prevalence was $4.3 \%$ in the younger and $2.3 \%$ in the older group. The data regarding comorbidity prevalence between depression and anxiety of the elderly vary between $2 \%$ and $9.5 \%$ [17]. In cases like this the functional status and the QOL are seriously damaged, and the feeling of loneliness is frequently present [16], [19]. Anxiety is most usually regarded as a factor predicting the onset of depression [20] while it can also be a part of phenomenology of depression at an older age without having any negative effects on functional status and mortality.

The QOL was for the purposes of this research tested by applying the WHO questionnaire WHOQOLBREF. The participants are tested in four domains regarding the QOL (physical and mental health, social relations, and environment). The participants hereby also assess the level of their satisfaction with life as a whole. More than half of the participants of this research claim to be dissatisfied or very dissatisfied with their QOL. Research also shows that mental and physical 
health of the elderly is strongly connected with general concept of oneself which consequently leads to greater satisfaction with the QOL [21].

Various psychological and social factors are reflected in the quality of ageing. The aging process influences innate personality traits, habits developed during one's lifetime as well as one's health selfassessment which directly reflects on the QOL. The individual assessment of QOL is connected with person's physical health, mental condition, selfsufficiency, social relations, and religious beliefs [17].

For the purposes of this research, WHOQOL questionnaires were used on participants mostly suffering from both physical and mental illnesses. One of the research parts was intended for patients suffering from diabetes whose therapy was recently changed from oral to insulin treatments. The QOL of the participants taking insulin is a bit lower than those of the patients who continue their treatments orally [22]. WHOQOLBREF questionnaires were used to test patients with various gastroenterological illnesses and the results have shown that their QOL is not at all disturbed by the illness itself, but by psychological factors [23]. This only proves that depression and anxiety truly are one of the factors that lead to the lowering of the QOL. It is easier for people to cope with these problems when they have a supportive environment which makes it easier for them to maintain their subjective perception of the QOL [24].

Perception of health is a very important part of the QOL and is regarded as a valuable indicator of the population's health condition, is, however, not the only factor regarding a person's QOL. This fact is supported by the findings of the research conducted so far in the Republic of Croatia [25].

The QOL at an old age, even though connected with health, does not necessarily have to depend on it [26]. Family and social connections are important for maintaining the QOL [27], which makes individuals with less social connections more susceptible to numerous health and social problems [28]. Moreover, the studies also emphasize the importance of social connections from a point of view of mental health protection [29], [30], marginalization prevention as well as insuring of social support [30].

The MMSE questionnaire was used as an instrument for quick assessment of cognitive abilities and dementia diagnostics. According to the results interpretation scale, 24 and over indicate a normal test result, which means that 83 (53\%) participants of this research have a normal test result, whereas test results of $73(47 \%)$ participants indicate the presence of a particular disorder. The QOL, of the participants whose test results indicate the presence of a particular disorder, is significantly lower in all the measured domains.

Lately, more and more research is conducted with the purpose of investigating positive features of mental health and their connection with the protective factors. The level of satisfaction with life is one of the most frequent measures of mental health. It is defined as cognitive evaluation of the component of the subjective feeling of welfare. This cognitive component is different from the emotional component, even though both are very frequently connected [31]. Furthermore, many findings show that emotions of pleasant hedonic tone, slightly, but consistently, increase as the person is getting older. At the same time, there is a decrease of the emotions of unpleasant hedonic tone that reach their maximum in early adulthood with a lowering tendency until the person reaches the age of 60 after which they do not change their levels anymore [32].

The values obtained by cognitive functioning questionnaire are closely connected with the QOL domains, the strongest connection being the one regarding mental health, and the weakest the one connected to social functioning.

Disturbed mental health is something people are afraid and ashamed of, they deny it and refuse to accept it and by doing so they sadly negatively influence the QOL of their social environment, most intensely their own and those closest to them. Healthy aging a syntagma, which sadly does not relate to most of the processes in the human body, consequently including mental health. It is, however, of great importance to mention that social support and quality family interactions can have a positive effect on the dignity of the elderly and at the same time act as a protective factor when it comes to mental health care [33].

The team of family medicine has a very important role when it comes to recognizing the acute, as well as chronic non-infectious illnesses. The mental health of the elderly can be improved by a variety of the preventive activities and healthy ageing process [34]. Promoting healthy lifestyle, which is to be started at an earlier age, improving physical and mental activities, avoiding smoking, moderately consuming alcoholic beverages, as well as early discovering and treatment of chronic non-infectious illnesses can contribute to better mental health. As far as health and mortality at the old age are concerned, researches have shown that relatively stable personality traits, social support, and positive health care are strongly connected with positive long-term health outcomes [35].

Both European and Croatian Gerontological findings have confirmed that one cannot neglect the codependence of an elderly person and their health preservation regarding the community one lives and is productive in. Functionally, capable older persons are extremely productive community members [36]. They can be used to share and transfer their knowledge, skills, and work experience onto the younger, but also older generations Old age is a time when life is characterized by new spiritual dimensions and advantages that did not exist in one's youth. Active healthy aging also includes 
one's ability to adjust to new circumstances, knowledge and constant learning and discovering of the advantages of the aging process and old age itself [36].

\section{Conclusion}

Sudden demographic changes and trends that follow modernization lead to many problems regarding care and welfare of the elderly. Having this in mind, the experts concerned with mental health are to have a prominent role when it comes to improving healthy aging and the QOL. What is more, their importance is to be even greater due to the fact that, even though, specific biological changes are unavoidable in the ageing process, it is beyond questioning that the person's ability to mentally adapt to the imposed changes are finally of greatest relevance when determining the QOL of the elderly.

Based on the research findings, it is to be concluded that the QOL of the elderly has been significantly lowered and that their life satisfaction level is very low. In Croatia, it is necessary that the family and general medicine physicians, as well as other experts having to do with the health protection of the elderly, be constantly educated in the field of gerontology and geriatrics, more specifically in the field of preventive measures, pharmacotherapy, and palliative geriatric care. Furthermore, it is important to promote intergenerational family relations and social connections in Croatia to maintain the QOL of the elderly.

\section{References}

1. Croatian Bureau of Statistics. Republic of Croatia; 2018. Available from: https://www.dzs.hr. [Last accessed on 2018 Mar 10].

2. Ministry of Health of the Republic of Croatia. National Strategy for Health Care Development 2012-2020. Republic of Croatia; 2012. Available from: https://www.zdravlje.gov.hr/programi-iprojekti/nacionalni-programi-projekti-i-strategije/ostali-programi/ national-health-care-strategy-2012-2020/2195.

3. Pečjak V, Sučević $Đ$, Fruk-Mundorfer S. Third Age Psychology. Zagreb: Prosvjeta; 2001.

4. Tordoff JM, Ailabouni NJ, Browne DP, Al-Sallami HS, Gray AR. Improvements in the prescribing of antipsychotics in dementia and psychogeriatric units in New Zealand. Int $\mathrm{J}$ Clin Pharm. 2016;38(4):941-9. https://doi.org/10.1007/s11096-016-0318-1 PMid:27241343

5. Kester R, Unützer J, Hogan D, Huang H. Antipsychotic prescribing patterns in a Medicare Advantage population of older individuals with dementia. J Ment Health. 2017;26(2):16771. https://doi.org/10.1080/09638237.2016.1244720 PMid:27841049

6. World Health Organization. Global Network of Age-Friendly Cities and Communities. Geneva: World Health Organization; 2018. Available from: https://www.extranet.who.int/agefriendlyworld/ who-network. [Last accessed on 2018 Mar 10]

7. Langa KM, Levine $\mathrm{D}$. The diagnosis and management of mild cognitiveimpairment:Aclinical review. JAMA. 2014;312(23):255161. https://doi.org/10.1001/jama.2014.13806

PMid:25514304

8. Singh A, Misra N. Loneliness, depression and sociability in old age. Ind Psychiatry J. 2009;18(1):51-5. https://doi. org/10.4103/0972-6748.57861

PMid:21234164

9. Lipovčan LK, Prizmić-Larsen Z. Quality of life, life satisfaction and happiness in Croatia in comparison to European countries. In: Ott $\mathrm{K}$, editor. Croatian Accession to the European Union the Challenges of Participation. Zagreb: Institute of Public Finances, Friedrich Ebert Stiftung; 2006. p. 189-208. Available from: http://www.ijf.hr/eng/ EU4/kaliterna-prizmic.pdf. [Last accessed on 2018 Mar 10].

10. Carr AJ, Gibson B, Robinson PG. Is quality of life determined by expectations or experience? BMJ. 2001;322(7296):1240-43. https://doi.org/10.1136/bmj.322.7296.1240 PMid:11358783

11. FolsteinMF,FolsteinSE,McHughPR.Mini-mentalstate:Apractical method for grading the cognitive state of patients for the clinician. J Psychiatr Res. 1975;12:189-98. https://doi.org/10.1002/ (sici)1099-1166(199805)13:5<285:aid-gps753>3.0.co;2-v PMid:1202204

12. Skevington SM, Lotfy M, O'Connell KA. The World Health Organization's WHOQOL-BREF quality of life assessment: Psychometric properties and results of the international field trial a report from the WHOQOL group. Qual Life Res. 2004;13(2):299310. https://doi.org/10.1023/B: QURE.0000018486.91360.00 PMid:15085902

13. United Nations. Department of Economic and Social Affairs. Population Division. World Population Ageing, 1950-2050. New York: United Nations; 2002.

14. Lučanin JD. Health psychology of ageing review of the field and of the research in Croatia. Klin Psihol. 2008;1(1-1):59-77.

15. Campos C, Rocha NB, Vieira RT, Rocha SA, Telles-Correia D, Paes $\mathrm{F}$, et al. Treatment of cognitive deficits in Alzheimer's disease: A psychopharmacological review. Psychiatr Danub. 2016;28(1):2-12. PMid:26938815

16. Van der Weele GM, Gussekloo J, De Waal MW, De Craen AJ, Van der Mast RC. Co-occurrence of depression and anxiety in elderly subjects aged 90 years and its relationship with functional status, quality of life and mortality. Int $\mathrm{J}$ Geriatr Psychiatry. 2009;24(6):595-601. https://doi.org/10.1002/gps.2162 PMid: 19031476

17. Schaub RT, Linden M. Anxiety and anxiety disorders in the old and very old--results from the Berlin aging study (BASE). Compr Psychiatry. 2000;41(2 Suppl 1):48-54. https://doi.org/10.1016/ S0010-440X(00)80008-5

PMid:10746904

18. Sinoff G, Werner P. Anxiety disorder and accompanying subjective memory loss in the elderly as a predictor of future cognitive decline. Int J Geriatr Psychiatry. 2003;18(10):951-9. https://doi.org/10.1002/gps.1004

PMid: 14533128

19. Schoevers RA, Beekman AT, Deeg DJ, Jonker C, van Tilburg W. Comorbidity and risk-patterns of depression, generalised anxiety disorder and mixed anxiety-depression in later life: Results from the AMSTEL study. Int J Geriatr Psychiatry. 2003;18(11):9941001. https://doi.org/10.1002/gps.1001

PMid: 14618550

20. Paukert AL, Pettit JW, Kunik ME, Wilson N, Novy DM, 
Rhoades HM, et al. The roles of social support and self-efficacy in physical health's impact on depressive and anxiety symptoms in older adults. J Clin Psychol Med Settings. 2010;17(4):387400. https://doi.org/10.1007/s10880-010-9211-6 PMid:21110074

21. Acton GJ. Well-being as a concept for theory, practice, and research. Worldviews Evid Based Nurs. 1994;E1(1):88-101. https://doi.org/10.1111/j.1524-475X.1994.00088.x

22. Pibernik-Okanović M, Szabo S, Metelko Z. Quality of life following a change in therapy for diabetes mellitus. Pharmacoeconomics. 1998;14(2):201-7. https://doi. org/10.2165/00019053-199814020-00008 PMid:10186460

23. Jokic-Begic N, Tadinac M, Hromatko I, Korajlija A. The subjective quality of life (SQOL) in gastroenterological patients. Psihol Teme. 2007;16:259-74.

24. Notenboom K, Beers E, van Riet-Nales DA, Egberts TC, Leufkens HG, Jansen PA, et al. Practical problems with medication use that older people experience: A qualitative study. J Am Geriatr Soc. 2014;62(12):2339-44. https://doi.org/10.1111/ jgs. 13126 PMid:25516030

25. Ćurković M, Dodig-Ćurković K, Erić AP, Kralik K, Pivac N. Psychotropic medications in older adults: A review. Psychiatr Danub. 2016;28(1):13-24. PMid:26938816

26. Garcia LM, Navarrro LM. The impact of quality of life on the health of older people from a multidimensional perspective. JAging Res. 2018;2018:4086294. https://doi.org/10.1155/2018/4086294

27. Olagnero M, Meo A, Corcoran MP. Social support networks in impoverished European neighbourhoods. Eur Soc. 2005;7(1):5379. https://doi.org/10.1080/1461669042000327027

28. Speer PW, Jackson CB, Peterson NA. The relationship between social cohesion and empowerment: Support and new implications for theory. Heal Educ Behav. 2001;28(6):716-32. https://doi.org/10.1177/109019810102800605

PMid: 11720274

29. Brissette I, Cohen S, Seeman TE. Measuring social integration and social networks. In: Social Support Measurement and Intervention. Oxford: Oxford University Press; 2000. p. 53-85. https://doi.org/10.1093/med: psych/9780195126709.003.0003

30. Böhnke P. Are the poor socially integrated? The link between poverty and social support in different welfare regimes. J Eur Soc Policy. 2008;18(2):133-50. https://doi. org/10.1177/0958928707087590

31. Kearns A, Forrest R. Social cohesion and multilevel urban governance. Urban Stud. 2000;37(5-6):995-1017.

32. Gana K, Bailly N, Saada Y, Joulain M, Alaphilippe D. Does life satisfaction change in old age: Results from an 8-year longitudinal study. J Gerontol Ser B Psychol Sci Soc Sci. 2013;68(4):540-52. https://doi.org/10.1093/geronb/gbs093

PMid:23103381

33. Davis MC, Zautra AJ, Johnson LM, Murray KE, Okvat HA Psychosocial stress, emotion regulation, and resilience among older adults. In: Handbook of Health Psychology and Aging. New York, US: Guilford Press; 2007. p. 250-66.

34. Milanović SM, Erjavec K, Poljičanin T, Vrabec B, Brečić $\mathrm{P}$. Prevalence of depression symptoms and associated sociodemographic factors in primary health care patients. Psychiatr Danub. 2015;2(1):31-7.

PMid: 25751429

35. Umberson D, Karas Montez J. Social relationships and health: A flashpoint for health policy. J Health Soc Behav. 2010;51(Suppl):S54-66. https://doi. org/10.1177/0022146510383501 PMid:20943583

36. del Barrio E, Marsillas S, Buffel T, Smetcoren AS, Sancto M. From active aging to active citizenship: The role of (age) friendliness. Soc Sci. 2018;7(8):134-50. https://doi.org/10.3390/ socsci7080134 